Bulletin of the AAS • Vol. 54, Issue 1 (Obituaries, News \& Commentaries, Community Reports)

\title{
Roy A. Tucker
}

\author{
Eric R. Craine ${ }^{1}$
}

${ }^{1}$ Western Research Company

Published on: Mar 01, 2022

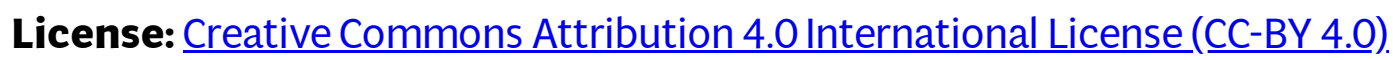


Roy Anthony Tucker died of pancreatic cancer on Friday March 5, 2021. He was 69 .

Roy was a remarkable friend and colleague who nearly completed a Ph.D. as a planetary scientist before realizing that he was, at heart, a superlative engineer whose true joy was in electronic fabrication and instrument design and implementation.

Born into post-war economic straits, his father had been a truck driver and his mother a just-of-age bride in Jackson, Mississippi. The family chicken farm instilled a love of animals and he kept chickens for fresh eggs until the end of his life. In an effort to improve the family finances his parents enrolled in a correspondence course in electronics, and embarked on a family business of repairing radios, TVs, and small appliances for neighbors and local residents. Among Roy's earliest recollections was sitting at their workbench, watching all that they did, and learning to solder wires even before he understood the function of the electronic components they connected.

As a boy he voraciously read spec sheets that his parents collected, and he thus informally began his electronics engineering career. With the advent of the transistor he became fascinated by electronic miniaturization and, as a youth, built and experimented with miniaturized radio transmitters that he was able to encapsulate and swallow to monitor the capsule's passage through his gastro-intestinal tract. With a characteristic laugh he told me about multiple repetitions of that particular experiment in which he was able to map gross folds in his intestine!

During this time the American probing of the solar system, both manned and unmanned, was in the process of ramping up, and, as with so many young men of that era, Roy was completely captivated by what seemed almost magical events. Late in his life he could still be moved to tears by recalling his delight and astonishment at watching televised images of the surfaces of the Moon and Mars being transmitted back to Earth - all the more remarkable to him as he was an avid ham radio operator 
(N4ABY) who well understood the history of radio communications and the very large strides it had made during his parents' and his involvement in radio technology.

After a family move to Memphis, Tennessee, Roy was introduced to astronomy by the Memphis Astronomical Society and subsequently enrolled at Memphis State University (1969) to pursue a degree in physics. In 1972 “...an extended Spring Break...” followed a low draft number and he continued his education in Thailand, courtesy of the United States Air Force (May 1972 - December 1975), where he fondly remembered learning how to maintain electronic countermeasures on B-52 bombers. We often talked about the technology of that era, interspersed with his opining that young Thai women were among the most beautiful in the world.

He returned to Memphis after three and a half years supporting the Air Force in the Vietnam War, and graduated in 1977 with a physics degree. Soon thereafter, he was in Santa Barbara attending the University of California where he was to earn a Master's degree in instrumentation design, which he completed in 1981. His M.S. program was punctuated by a summer internship (1979) in Tucson, where he became interested in asteroids and planetary sciences.

He returned to Tucson following completion of his M.S. degree and joined the staff at the Multiple Mirror Telescope, in addition to taking further graduate courses at the University of Arizona (U of A). While searching for a more permanent situation, he spent time as a principal engineer for various projects at the $U$ of A Department of Physiology, at Haleakala Observatory in Maui, at Kirtland AFB in Albuquerque, and at Steward Observatory with the photopolarimeter project. The latter eventually took him to Moscow to support observations with that instrument at the 5-m telescope. For the next few years he was involved in many astronomical projects, including a stint at the National Solar Observatory from 1997 to 2002 developing new cameras for the GONG helioseismology program.

In the early 1980s I had left Steward Observatory to run a technology company that could capitalize on some patents that followed on my work at the U of A. When I mentioned to my friend (and principal user of the Steward photopolarimeter), Dr. Santiago Tapia, that I was in search of a consulting engineer to help with some of our projects he immediately indicated that I needed to meet a fellow named Roy Tucker. Santiago arranged the meeting which led to an almost 35 year friendship, numerous collaborative projects, and a large number of pizzas, the total number of which we finally decided we could not even estimate with any accuracy. 
Among the projects that occupied us in the 80's was application of CCDs to a variety of medical problems, and it was in part with these projects that Roy began to learn about CCDs. We eventually built a small number of different models of cameras, some of which we applied to freelance astronomy projects. My first memorable pizza with Roy was on a truck hood at Tumamoc Hill Observatory during a break in making time lapse movies of the rotation of Mars. I distinctly recall that the very cold pizza was pineapple, ham, and anchovies. We later made high time-resolution images of a stellar occultation of a star by Saturn's rings, again using one of our early cameras.

Around 1996 he founded his personal home observatory, Goodricke-Pigott Observatory (GPO), named for prominent figures in the history of the discovery and study of variable stars. It was a labor of love, with the emphasis on labor. The two of us burned out the bearings on a portable cement mixer making the many loads of concrete required for the pads and pier foundations. He was a big believer in fail safe engineering with the result that there is a lot of rebar under those telescopes. I pity the person who eventually has to break up those supports!

Roy's asteroid discoveries came slowly with his first GPO telescope, and he began to envision a more sophisticated instrument. Those visions would manifest in the evolution of the Moving Object and Transient Event Search System (MOTESS), arguably the signature achievement of his very productive life. MOTESS started with the design of a custom CCD camera, of which some were sold through Roy's consulting business. For MOTESS, the camera was to be operated in time delay integration (TDI) mode, meaning that it, and the telescope that fed it a stream of photons, would be fixed to point at a specific altitude and azimuth, and the image readout would be timed to match the rotation rate of the Earth.

The telescopes (and cameras) were of Roy's design, incorporating a clever mixed thermal expansion set of materials that compensated temporal focus changes in the system. He loved telling people that he only focused the system about once a year. Roy also designed and implemented the ad hoc software required for telescope control and data handling. The whole was integrated into the "Mini-MOTESS", a single test-bed scale model of the eventual telescopes, which was to serve as proof-of-principle, and later was used for other research projects of its own.

The full-up, three-telescope MOTESS system was placed in operation in 2001, and almost immediately Roy's production of new asteroid discoveries sky-rocketed! This work continued for a few years after which he had another fateful idea. I had been working with getting the Global Network of Astronomical Telescopes (GNAT) up on its 
feet since about the beginning of GPO, but having less luck than Roy was. GNAT was trying to set up commercial automated telescopes to provide an observational data stream for the study of variable stars, but the accessible commercial systems were not yet sufficiently mature. At several of our frequent lunches, Roy urged me to consider MOTESS as a source of such data.

After further prodding by Roy, I finally saw the light and we began exploring variable stars in the MOTESS data. This process was given an enormous boost by Adam Kraus, then an undergraduate, who put together the first GNAT data pipeline that enabled creation of the MG1 variable star catalog (ca. 2006-7). This effort alone yielded discoveries of over 26,000 variable star candidates, most not previously recognized. The eighth MG survey is currently underway, 20 years after the start of the first!

By 2010 Roy's asteroid hunting returns were rapidly diminishing, thanks mostly to large scale, well-funded competing surveys. During his peak years of asteroid success he discovered over 700 verified objects, with naming rights for several hundred of them. In addition, he discovered a couple of comets, and was co-discoverer of the NEO Apophis.

With the decline of his asteroid discovery days Roy became immersed in follow-up observations of variable stars in collaboration with various members of GNAT. On observing runs together we indulged his love of classic sci-fi or anime movies; one of his favorites being Forbidden Planet, for which he could recite much of the dialog and never failed to note the contributions of Anne Francis! The pinnacle of this work was his 20-year study of the variable star MG1-688432, an unusual binary star with an extremely active light curve. Fortunately, he lived long enough to see the acceptance of the first paper on this star by the Astrophysical Journal Supplement Series.

Roy was a prolific observer. For the last two decades of his life he observed on virtually all clear nights, usually simultaneously managing operation of 3-5 different telescopes at a time. This was enabled by the use of semi-automated systems of his design.

Our last observing run together was a week of spectroscopy with the Vatican Advanced Technology Telescope (VATT) spectrograph of the Vatican Observatory at Mount Graham International Observatory. Very shortly afterwards he was diagnosed with advanced stage 4 pancreatic cancer.

Roy married twice. His first wife, Vera, he met while working in Moscow. His second wife, Jennifer, was a Chinese Navy veteran, whom he met in China. He had no children. 
Roy was a skilled engineer, an innovative scientist, and an endlessly creative mind. He was a great friend who will be truly missed by many. Toward the end we talked about how he might soon have a revealing new perspective on the universe. I can only imagine his delight! By curious coincidence his favorite asteroid, Apophis, made its closest recent approach to Earth on the day Roy died. 